\title{
CORRELATION OF BLASTING PERFORMANCE WITH LOADING AND CRUSHING TIME TO MINIMIZE ENERGY CONSUMPTION
}

\author{
Alaba, O. C. \\ Federal University of Technology, Akure, \\ Department of Mining Engineering, Nigeria \\ Senior Lecturer, Doctor of Mine Health, Safety and Environment, \\ Email: ocalaba@futa.edu.ng; \\ Phone No: +234 8062777774 \\ Abdulraman, S.O. \\ Kwara State University, Malete \\ Department of Materials Science and Engineering, Nigeria \\ Senior Lecturer, Doctor of Surface Mining, \\ Email: sikiru.abdulraman@kwasu.edu.ng; \\ African University of Science and Technology, Abuja, \\ Department of Materials Science and Engineering, Nigeria \\ Visiting Faculty, Phone No: +234 8033979980
}

\begin{abstract}
Blasting performance with loading and crushing time were correlated in order to minimize energy consumption in quarry operation. A measure scaled object was placed within the muck pile of blasted rock fragments. Digital camera was used to take the photograph of the scaled object and the blasted rock fragments before the commencement of loading and crushing operations. The data collected were subjected to fragmentation analysis using split desktop App while the correlation analyses were carried with Microsoft Excel App. The fragmentation and distribution analysis showed that the fine cut off sizes are $8.75 \mathrm{~cm}, 9.55 \mathrm{~cm}, 7.58 \mathrm{~cm}, 8.58 \mathrm{~cm}$ and $11.75 \mathrm{~cm}$ while their mean size distribution are $35.99 \mathrm{~cm}, 10.25 \mathrm{~cm}, 24.86 \mathrm{~cm}$, $16.78 \mathrm{~cm}$ and $16.10 \mathrm{~cm}$ respectively. The $\mathrm{R}$ squared values $\left(\mathrm{R}^{2}\right)$ obtained during the correlation of digging time with size of fragmentation passes (P50), mean deviation and bucket passes were given as $0.94,0.39$ and 0.63 with p-values of $0.00,0.34$ and 0.82 respectively. Consequently, the $\mathrm{R}^{2}$ values during the correlation of crushing time with P50, mean deviation and range were specified as $0.64,0.62$ and 0.27 with p-values of $0.00,0.11$ and 0.07 respectively. The study therefore established that only the regression equation for P50 is statistically significant while statistically insignificant for mean deviation, range and number of bucket passes.
\end{abstract}




\section{Introduction}

In recent times, the campaign for energy efficiency in mining industry is yielding good results. Energy consumption in mining contributes to operational costs in all stages of ore recovery process: blasting, excavation, materials transfer and haulage, comminution, ventilation and dewatering [1]. In order to optimize energy in mining sector, Energy Mass Balance (EMB) has been adopted and incorporated into mining industries activities. The EMB systematically collects and analyses data on energy use and investigates where losses occur [2]. This suggests that the EMB can only be used as an energy saving strategy in mining industry but it cannot predict the outcome of any system of operations and cannot really access blast results to show energy losses during blasting.

Also, some optimization models have emerged in the mining industry that are operation specific such as loading, hauling and crushing $[3,4,5]$. For instance, Leighton Contractors Pty Ltd developed a series of mass and energy equations to improve the energy saving initiatives in haulage operations during mine design [6]. Fortescue Metals Group identified and quantified the energy costs associated with stopping haul trucks [7] while Downer EDI Mining developed performance indicators that use an 'equivalent flat haul' calculation to account for elevation changes on a specific mine route [8]. These models have achieved numerous results but they can only be used to evaluate the energy optimizations for haulage operations.

As mentioned earlier the major limitation that unites all the models discussed above is that they actually correct energy wastage in operations but they do not prevent the energy wastage. It does not agree with the saying that "prevention is better than cure. Fragmentation control is the best way to prevent energy wastage in the entire mining operations and it can be done through optimization of blasting performance [9]. The reason for this assertion is based on the fact that the quality of the fragmentation after blasting affects both loading, haulage and crushing. The overall cost effectiveness of the production operations is compatible with optimization of drilling and blasting parameters [10]. Kuz-Ram fragmentation model is the closest mining based model that predicts fragmentation performance [11]. It has helped blasting engineers round the world in predicting the outcome of a blast and energy used up in blasting. The basic limitation of the 
model is that it cannot predict the energy consumption in subsequent mining operations like: loading, haulage and crushing.

Since, most of the previous studies focused much on the correction of energy wastage in operations with little attention on the prevention of energy wastage, this study therefore provides opportunity to advance our knowledge on energy correction and prevention of energy wastage in loading and crushing operations through optimization of blasting performance

\subsection{Overview of Energy Consumption in Mining and other In- dustrial Sectors}

Energy consumption is one of the key determinants of operational cost in mining and other industrial sectors [12]. Recent investigation showed increase in daily demand of energy in mining and other industrial sectors. In 2017, the world total energy supply was 162,494 TWh of which only 113,009 TWh was finally consumed [13]. Out of this, mining sector consumed approximately $11 \%$ of the world total energy [14]. In 2012, about 2-3\% of the total energy supplied in USA was consumed by mining sector [15] while $8 \%$ of the total energy supplied in South Africa was consumed by mining sector in 2010 [16]. The corresponding number in Canada in 2009 was $12 \%$ [17]. The world's largest individual energy consumer is China, which also produces $40 \%$ of the world's minerals [18].

In 2025 about $36.2 \%$ of energy are projected to be consumed by new mining project [1]. It was also projected that about $41.1 \mathrm{TWh}$ of energy would be used in 2025 by copper mining industry in Canada which is an increase of $95.5 \%$ recorded in 2013 [19]. In all stages of mining operation, mineral processing consumes most energy worldwide and it accounts for 4-5\% of the total electrical energy produced globally $[1,20]$. In mineral processing operation, loading and crushing are the principal energy consumers with $40 \%$ of energy consumed in mineral processing operations and $4 \%$ of the world's total electrical energy [21-24].

\section{Material and Methods}

\subsection{Description of the Study Area}

Francisca Muinat (FM) Quarry is the case study area and is situated within the longitudes $5000^{\prime} \mathrm{E}$ and $5017^{\prime} \mathrm{E}$ and latitudes $7010^{\prime} \mathrm{N}$ and $7020^{\prime} \mathrm{N}$ about $4 \mathrm{~km}$ to Akure on Aaye-Ijare road as shown in 
Figure 1. The outcrop is made up of migmatite intruded by three petrological varieties of older granites under the Basement complex of South-western Nigeria. Francisca Muinat Quarry has a joint venture partnership with the Chinese. It is a commercial aggregate quarry that produces different sizes of granite aggregate for construction purposes

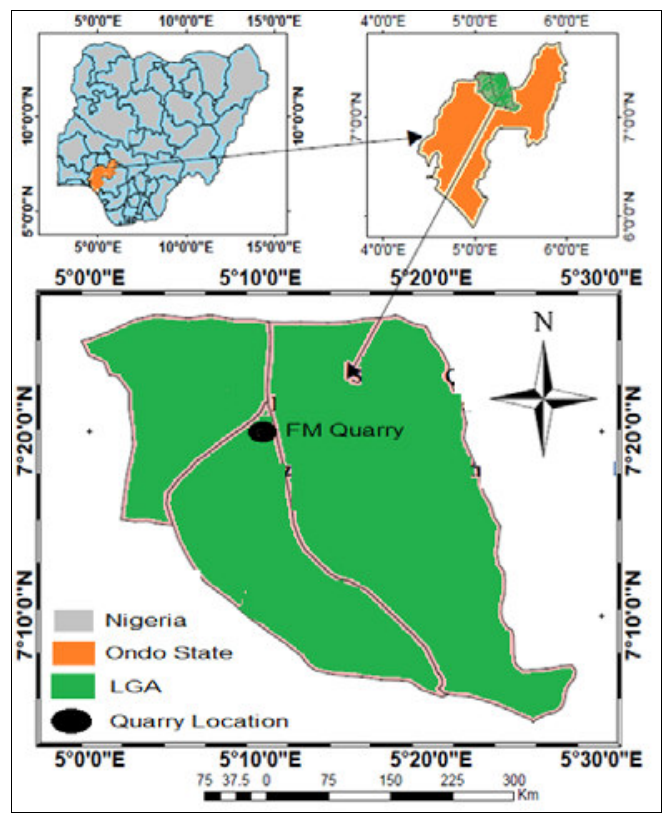

Fig. 1. Location of study area

\subsection{Data Collection Procedures}

\section{(a) Loading and Haulage Procedures}

(i) A scaled object was placed within the blasted rock fragments and digital images of the fragmented rocks with the scaled object were taken before the commencement of loading and haulage operation.

(ii) The time taken for the loader to dig and scoop fragmented rocks from the muck pile to the loader for each bucket was recorded.

(iii) The swing time to and fro (time taken in digging and loading the dump truck and then coming back to muck pile again) was recorded. 
(iv) The number of buckets to fill the dump truck was recorded by recording the digging time for each bucket.

(v) The travel time of the dump truck with the loading fragments from pit to crusher hopper was recorded

(vi) The travel time for the dump truck to travel back to the pit empty was recorded

(vii) The above procedures were repeated for twelve times in order to obtain adequate data for the analysis

(b) Crushing Procedures

(i) A scaled object was placed within the blasted rock fragments in the crusher hopper and digital images of the run off mine fed into the jaw plates was taken before the commencement of crushing operation

(ii) The time to crush each of the fragmented rocks in the crusher was taken and recorded

(iii) The above procedures were repeated for twelve times in order to obtain adequate data for the analysis

\subsection{Data Analysis}

The variables P50, range, mean deviation and p-value were used to carry out correlation analysis using split desktop App and Microsoft excels application. $\mathrm{P}_{50}$ was used because its value can be obtained from Kuz - ram model to predict blasting performance while range and mean deviation were used to predict the size distribution of fragmented rocks. The image photographs obtained from field were uploaded on the split desktop App. The split desktop App was used to scale and delineate the images for size distributions analysis. This was used to determine the sizes at which $50 \%\left(\mathrm{P}_{50}\right)$ of the particular fragment passes. The mean deviation and the range were calculated while their $R$ squared values and the $\mathrm{P}$ values for the models derived were observed. The variables $\mathrm{P}_{50}$, range, mean deviation for all the images were plotted against time taken to dig, load and crush the fragments using Microsoft excel App. The linear regression lines obtained from Microsoft excel App and their respective $R$ squared values with $p$-values were used for the correlation analysis with blasting performance. The $R$ squared values show how well the points fit the regression lines. The $R$ squared value indicates how well the points plotted on the graph agrees with the regression line, which informs the decision of the analyst on whether to rely on the equation or not. $R$ squared values above 50 percent is quite reliable and the values 
under 50 percent is not reliable. The p-values show the level of statistical significance of the model.

\section{Result and Discussion}

\subsection{Fragmentation and Distribution Curves Analysis}

The results of the fragmentation and size distribution analyses using split desktop App were presented in Figures 2-7. The fainted red lines in the figures indicate fine particles while the bold red lines indicate fragmented rocks. The fine cut off indicates the size below the fragment that considered as fine particles. Figure 3 shows that the fine cut off of $8.75 \mathrm{~cm}$ with mean size of $35.99 \mathrm{~cm}$ while Figure 4 shows a fines cut off of $9.55 \mathrm{~cm}$ with mean size of $10.25 \mathrm{~cm}$. Figures $5-7$ show fine cut off sizes of $7.58 \mathrm{~cm}, 8.58 \mathrm{~cm}$ and $11.75 \mathrm{~cm}$ respectively while their mean sizes are $24.86 \mathrm{~cm}, 16.78 \mathrm{~cm}$ and $16.10 \mathrm{~cm}$ respectively

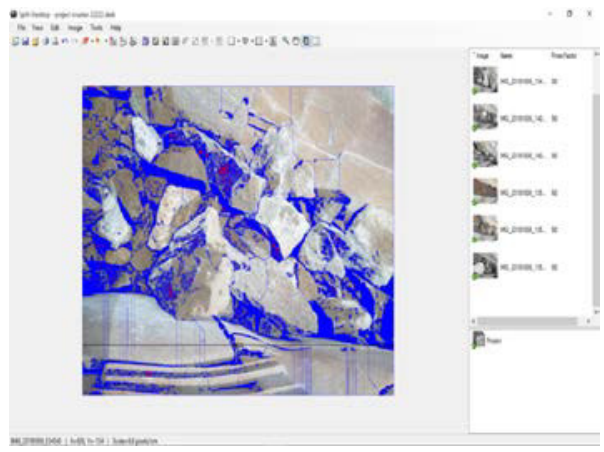

Fig. 2. Delineation picture using spilt desktop application

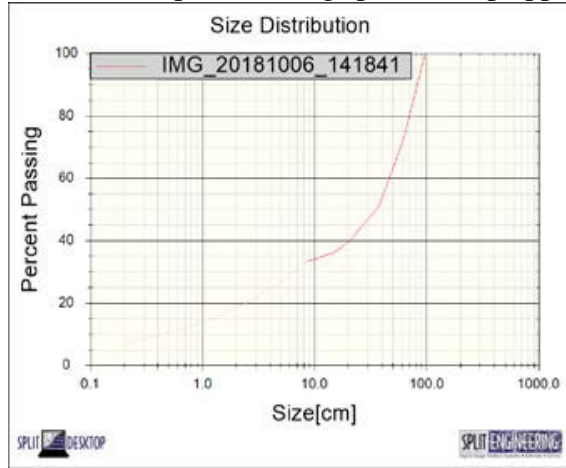

Fig. 3. Fragmentation analysis for image (1) 


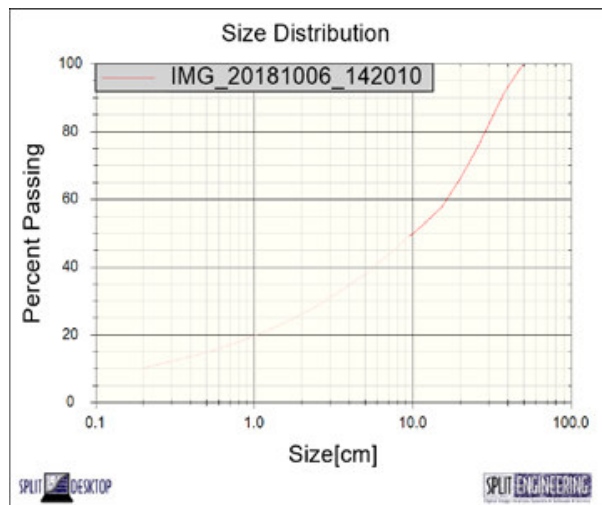

Fig. 4. Fragmentation analysis of image (2)

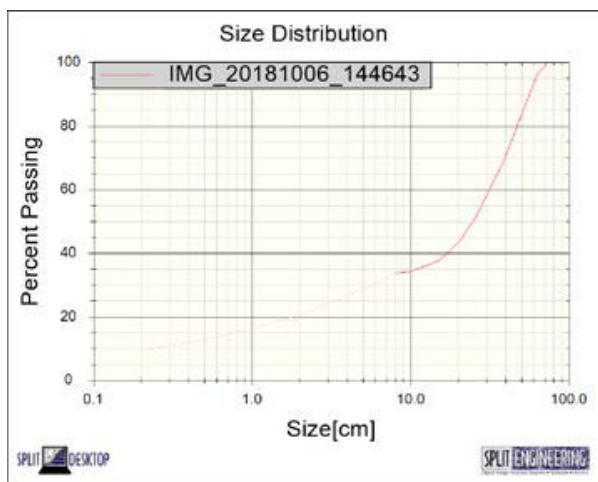

Fig. 5. Fragmentation analysis of image (3)

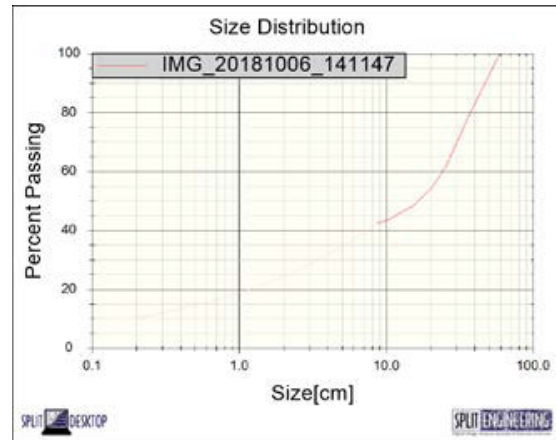

Fig. 6. Fragmentation analysis of image (4) 


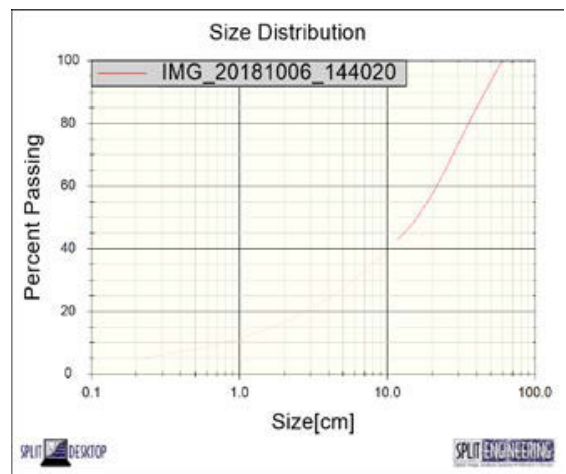

Fig. 7. Fragmentation analysis of image (5)

\subsection{Correlation of loading time with fragmented size}

The average time taken for digging during loading was correlated with the size at which $\mathrm{P}_{50}$ of the muck pile passes as presented in Figure 8. The regression equation of average digging time and $\mathrm{P}_{50}$ was given as $y=0.0036 x+0.1242$ with $R$-square value $\left(R^{2}\right)$ of 0.9403 . This demonstrated that there is good correlation between the average digging time and sizes at which P50 of the particular muck pile passes as $94.0 \%$ of $R$ squared value $\left(R^{2}\right)$ of the two variables formed the regression line. The calculated p-value is given as $p<0.00$ which means the two variables are statistically significant.

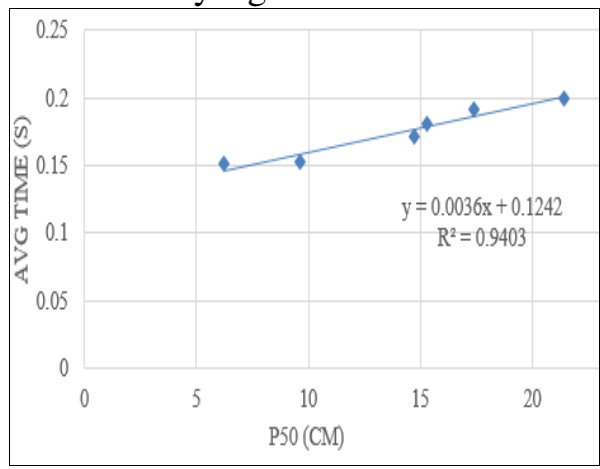

Fig. 8. Correlation between average digging time and P50

Figure 9 presents the correlation of average digging time with the mean deviation. The regression equation of average digging time and mean deviation of size distribution of the muck pile was given as 
$y=0.0055 x+0.106$ with $R^{2}=0.3932$. This substantiated that there is no good association between the digging time and size distribution of the muck pile as only $39.0 \%$ of the two variables aligned to the formation of regression line. At the same time, the calculated p-value is given as 0.34 which established that the two variables are statistically insignificant.

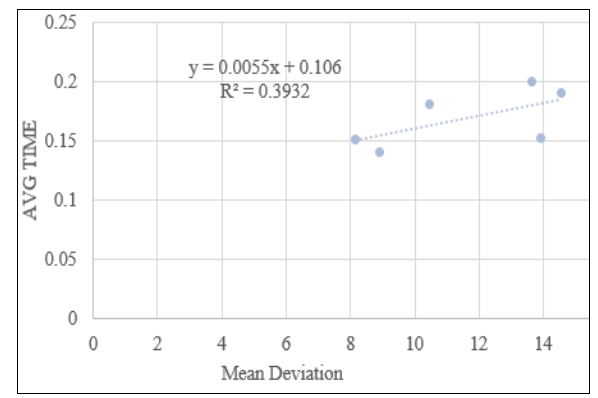

Fig. 9. Correlation between average digging time and mean deviation

The relationship between the average digging time and number of bucket passes during the loading of muck pile is presented in Figure 10. It was discovered that the regression equation between the two variables is given as $y=-0.0548 x+0.5982$ with $R^{2}=0.6364$. This affirmed that there is a good relationship between the digging time and the number of bucket passes during the loading operations as $63.0 \%$ of the two variables formulate the regression line. The estimated p-value was given as 0.82 which proved that the two variables is not statistically significant.

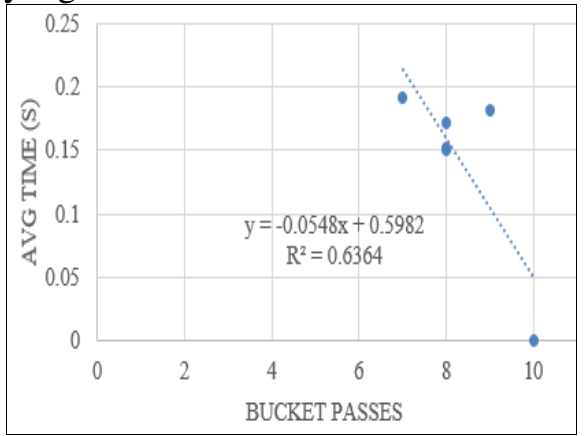

Fig. 10. Correlation between average digging time and number of bucket passes 


\subsection{Correlation of crushing time with fragmented size}

The time taken to crush the run off mine in the crusher is plotted against P50 as shown in Figure 11. The regression equation of blasting performance from the figure was given as $y=0.0276 x+0.3566$ with $\mathrm{R}^{2}$ value of 0.6408 . This means there is good relationship between the time taken to crush the run off mine in the crusher and sizes at which P50 of the particular fragment passes as $64.0 \%$ of $\mathrm{R}$ squared value $\left(\mathrm{R}^{2}\right)$ of the two variables aligned to form the regression line. The calculated $\mathrm{p}$-value is given as $\mathrm{p}<0.00$ which means the two variables are statistically significant.

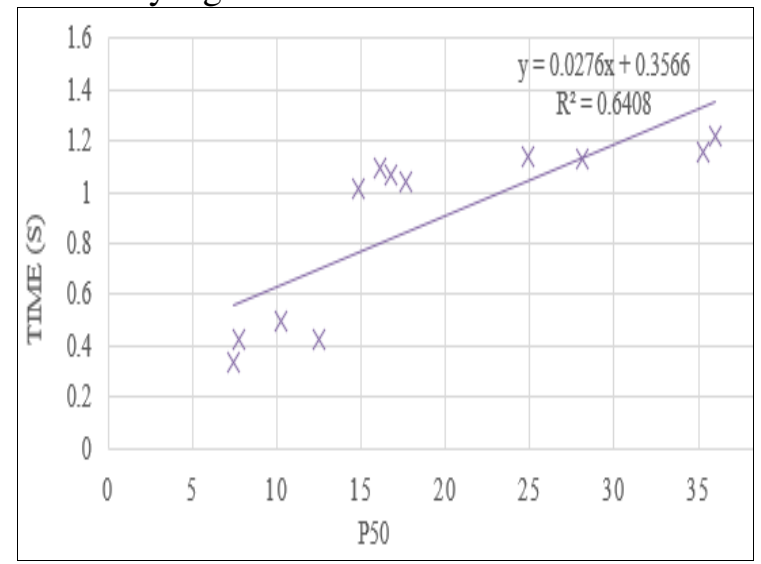

Fig. 11. Correlation between the time to crush and $\mathrm{P}_{50}$

The time taken to crush each of the muck pile loaded in the crusher hopper was correlated with the mean deviation as shown in Figure 12. The regression equation of how much the various fragments deviates from the mean size $\left(\mathrm{P}_{50}\right)$ of the stock of materials was given as $y=0.0547 x+0.1345$ with $R^{2}=0.6212$. This presents that there is good correlation between the time taken to crush each of the muck pile dumped in the main hopper and the fragmentations distributions of the muck pile dumped in the hopper as $62.0 \%$ of $R^{2}$ value of the two variables agreed to form the regression line. The $\mathrm{p}$-value for the regression was given as 0.11 which is $p>0.05$. Therefore it can be deduced that the two variables are statistically insignificant. 


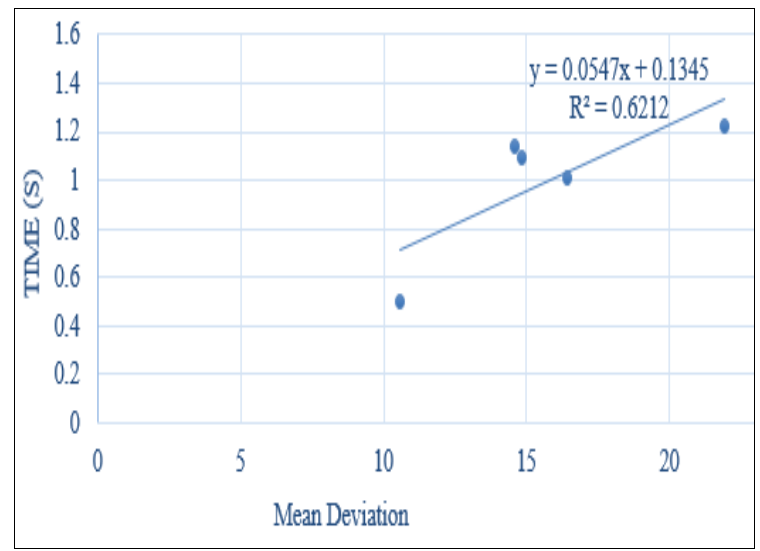

Fig. 12. Correlation between the time to crush and mean deviation

The relationship between the times taken to crush each trip of feed material and the range of sizes of the fragments were correlated as shown in Figure 13. The regression equation of range of sizes of the fragment was given as $y=0.0103 x+0.1763$ with $R^{2}=0.2772$. This establishes that there is no correlation between the time taken to crush each trip of feed material and range of sizes of the fragments (difference between maximum and minimum sizes of the fragments) as $27.0 \%$ of $R^{2}$ value of the two variables formulate the regression line. Meanwhile, the calculated p-value is given as 0.07 which means the two variables are statistically insignificant

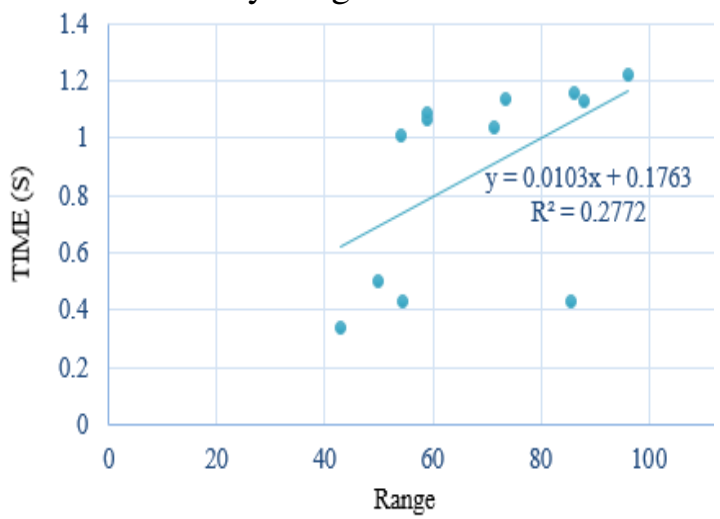

Fig. 13. Correlation between the time to crush and range 


\section{Conclusion}

This study was set out to correlate blasting performance with loading and crushing time in order to minimize energy consumption in quarry industry. The study therefore concluded as follows:

(i) The fine cut off values of fragmentation and distribution sizes using split desktop App are given as: $8.75 \mathrm{~cm}, 9.55 \mathrm{~cm}, 7.58 \mathrm{~cm}, 8.58$ $\mathrm{cm}$ and $11.75 \mathrm{~cm}$ while their mean size are $35.99 \mathrm{~cm}, 10.25 \mathrm{~cm}$, $24.86 \mathrm{~cm}, 16.78 \mathrm{~cm}$ and $16.10 \mathrm{~cm}$ respectively.

The correlation of loading time with fragmented size established that the regression equation of average digging time and $\mathrm{P}_{50}$ had an $R$ square value $\left(R^{2}\right)$ of 0.9403 with p-value of 0.00 which means the two variables are statistically significant. Meanwhile, the regression equation of average digging time and mean deviation of the muck pile had an $R^{2}$ value of 0.3932 with p-value of 0.34 which established that the two variables are statistically insignificant.

The regression equation between the average digging time and number of bucket passes during the loading of muck pile had an $R^{2}$ value of 0.6364 with p-value of 0.82 which proved that the two variables is not statistically significant.

(ii) The correlation of crushing time with fragmented size ascertained that the regression equation of blasting performance had an $\mathrm{R}^{2}$ value of 0.6408 with $p$-value of 0.00 which means the two variables are statistically significant.

Consequently, the regression equation of how much the various fragments deviates from the mean size (P50) of the stock of materials had an $\mathrm{R}^{2}$ value of 0.6212 with $\mathrm{p}$-value of 0.11 which means the two variables are statistically insignificant. The regression equation of range of sizes of the fragment had an $\mathrm{R}^{2}$ value of 0.2772 with $\mathrm{p}$-value of 0.07 which means the two variables are statistically insignificant. 


\section{References}

1. Jeswiet, J., Szekeres, A. Energy Consumption in Mining Comminution. 23rd CIRP Conference on Life Cycle Engineering, Procedia CIRP 48 (2016) 140 - 145

2. Energy Efficiency Opportunities (EEO). Energy-Mass Balance: Mining, Version 1.0, Published by Department of Resources Energy and Tourism (DRET),

Commonwealth of Australia, (2010):1-52. Available at https://www.energy.gov.au/sites/default/files/energy-mass_balance_mining.pdf,

3. Kecojevic, V., Komljenovic, D. Haul Truck Fuel Consumption and CO2 Emission under Various Engine Load Conditions. // Mining Engineering. 62. 12(2010)44-48.

4. Numbi, B; Xia, P. X. System's optimization model for energy management of a parallel HPGR crushing process. Applied Energy 149(2015)133-147

5. Verma, O. P., Mohammed, T. H., Mangal, S., Manik, G. Minimization of energy consumption in multi-stage evaporator system of Kraft recovery process using Interior-Point Method. Energy, 129(2017)148-157

6. Britton, M. Energy Efficiency Metrics in Mine Design. CEED Seminar Proceedings, (2012):55-60. Available at: http://ceed.wa.edu.au/wpcontent/uploads/2017/02/Energy-Efficiency-Metrics-in-Mine-Design-Britton.pdf

7. Cawley, T., Wilkinson, S., Pero, L., Parminter, G., Browning, R. and McDonald, S. Analyses of Diesel Use for Mine Haul and Transport Operations. DOI: $\quad 10.13140 /$ RG.2.1.1875.8008 (2011):1-21. Available at: https://www.researchgate.net/publication/303370988_Analyses_of_Diesel_Use_for_ Mine_Haul_and_Transport_Operations

8. Ali, S., Saiied, M.A., Mehmet, S.K and Peter, K. Reducing Fuel Consumption of Haul Trucks in Surface Mines Using Artificial Intelligence Models, in Naj Aziz and Bob Kininmonth (eds.), Proceedings of the 16th Coal Operators' Conference, Mining Engineering, University of Wollongong, 10-12 February 2016, 477-489

[9] Doktan, M. Impact of Blast Fragmentation on Truck Shovel Fleet Performance. 17th International Mining Congress and Exhibition of Turkey- IMCET2001. (2001)375-379

9. Gheibie, S., Aghababaei, H., Hoseinie, S.H and Pourrahimian, Y. Modified Kuz-Ram fragmentation model and its use at the Sungun Copper Mine. International Journal of Rock Mechanics and Mining Sciences, Volume 46, Issue 6, September 2009, Pages 967-973 https://doi.org/10.1016/j.ijrmms.2009.05.003

10. Michael J. E; David A. W. The state of natural gas. Journal of Natural Gas Science and Engineering 1(2009):1-13 
11. International Energy Agency (IEA). Key world energy statistics, (2019)636. Available on https://webstore.iea.org/key-world-energy-statistics-2019.

12. Kirschke, J. Energy urgency: Why the global mining industry is embracing renewables (2017). Available at https://nextbillion. Net/ energy-urgency-why-theglobal-mining-industry-is-embracing-renewables

13. Worrell, P., Blinde, M., Neelis, E., Blomen, E.M. Energy Efficiency Improvement and Cost Saving Opportunities for the U.S. Iron and Steel industry: An ENERGY STAR ${ }^{\circledR}$ Guide for Energy and Plant Managers, LBNL-4779E (Berkeley, CA: Lawrence Berkeley National Laboratory, Environmental Technologies Division, October 2010), Available at:https://www.energystar.gov/ia/business/industry/Iron_Steel_Guide.pdf.

14. Johnson, D., Fourie, S. An overview of energy efficiency in South African hard rock mining (2012)1-14. 10.1109/SAEEC.2012.6408583

15. Natural Resources Canada (NRC). "Energy Efficiency Trends in Canada, 1990 to 2009," (2012) [Online]. Available at: http://oee.rncan.gc.ca/publications/statistics/trends11/chapter5.cfm?attr=0

16. Reichl, C., Schatz, M., Zsak, G. "World Mining Data -Welt bergbau Daten Minerals Production /Rohstoffproduktion (2014)," Vienna

17. Wang, C., Nadolski, S., Mejia, O., Drozdiak, J., Klein. B. "Energy and cost comparisons of HPGR based circuits with the SABC circuit installed at the huckleberry mine". 45th Annual Canadian Mineral Processors Operators Conference, Ottawa, Ontario, Jan 22-24, (2013)121.

18. Fuertstenau, D.W., Abouzeid, A-ZM. Role of feed moisture in highpressure roll mill comminution. Int J Miner Process; 82(2007)203-210

19. Salazar, J.L., Valdés-González, H., Vyhmeister, E., Cubillos, F. Model predictive control of semiautogenous mills (SAG). Miner. Eng. 64(2014)92-96

20. Energy EXchange (EXX). Crushing energy costs in the mining sector (2015). Available at: https://www.eex.gov.au/2013/11/crushing-energy-costs-in-themining-sector

21. Gelenbe-Erol, Y. The impact of information technology on energy consumption and carbon emissions. Ubiquity, (2015)1-15

22. Eduardo, V., Lorenzo, R., Roman, R., Carlos, F., Fernando, C., Héctor, V. Modeling and energy-based model predictive control of high pressure grinding roll. Minerals Engineering, 134 (2019) 7-15 